\title{
A review-canna the wonder plant
}

\section{Introduction}

Plants have a unique role for the existence of all heterotrophic organisms including human population. For sustainable development it is indispensable to stop the loss of biodiversity connected with climate changes and anthropogenic activities. All of the phytochemicals can be availed from many flowering as well as non flowering plants. This property in a plant is specifically due to presence of some chemical entities as anthocyanins, carotenoids and flavonoids, indigoids, etc. As a matter of fact they are literally thousands of different compounds and metabolites in a plant known as phytochemicals and impart some of the special properties of plants viz. Color, fragrance and various medicines. Among phytochemicals, anthocyanins and betalains play important roles both in plant physiology, visual attraction for pollinators and seed dispersers, but also in food mainly defining its aesthetic value. Since anthocyanin and betalain structures allow predicting only part of their appearance, additional chemical and anatomical functions are required to modulate the appearance of plants and colored food. Physiological effects that the same pigments exert in plants are supposedly similar to those which they show in humans following ingestion of colored food. Therefore, anthocyanins and betalains both in fresh and also processed fruit and vegetables serve two functions: They improve the overall appearance, but also contribute to consumers' health and well-being. ${ }^{1}$ Plants produce thousands of different compounds through the secondary metabolism pathways. Since many of these products are obtained by direct extraction from plants that are cultivated in the field or sometimes even collected in their original habitat, several factors can alter their yield. The use of plant cell cultures has overcome several inconveniences for the production of secondary metabolites. Organized cultures, and especially root cultures, can make a significant contribution to our understanding of secondary metabolism. The natural pigment belongs to various classes of natural products like polyphenols, carotenoids, indoles etc. With increasing demand and awareness, analysis procedures, by which the components are assessed, are to be developed. Most of these compounds can be analyzed by a combination of specific extraction procedures, chromatography and spectrophotometry.

A flower or dye yielding part of plant can be used for this purpose. Canna or Indian shot which is a native, robust perennial herb, having typically red flower petals which can be used for dye as well as edible dye purpose as shown in Figure 1. Canna indica is an age-old plant, cultivated domestically, belongs to monocotyledonous Canna family Canaceae having red flower and have phytochemicals viz. flavonoids and anthocyanins. The color extracted from Canna flower petals can be used as food dye. Fabric dye from Canna has already been obtained and successfully dyed on fabric. Technique of extraction of the red pigment from Canna has been demonstrated, and best conditions of extraction were illustrated.

The other species of Canna, i.e., Canna edulis, is popularly grown in Carribbean region and tropical America. Its rhizome is tuberous and starchy which is boiled and eaten. The tuber is also ground into flour and made into cakes. Starch of this rhizome is also commonly sold. Nowadays starch of edible Canna (Canna edulis) is used in making noodles also. There are several examples, which show that edible
Volume 4 Issue 2 - 2018

\section{Padma SVankar, Jyoti Srivastava \\ Indian Institute of Technology, India}

Correspondence: Padma S Vankar, Indian Institute of

Technology, Kanpur-2080 I6, India,

Email padma.vankar@gmail.com

Received: December 21, 2017 | Published: March 23, 2018

Canna (Canna edulis) as complementary starch is good food material. Canna is grown for the sole purpose of extracting starch from its tuber as starch of Canna has largest known granules (30-100), resulting in fast setting, its paste was also found more stable.

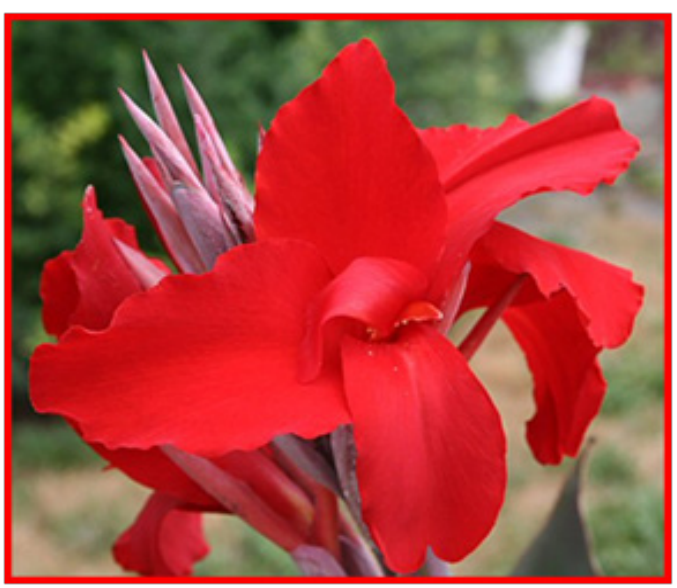

\section{Figure I Canna Flower}

The chemical composition and physicochemical properties of starches isolated from three cultivars (Japanese-green, Thai-green and Thai-purple) of edible Canna rhizomes by Thitipraphunkul et al. ${ }^{2}$ (I) Scanning electron microscopy investigations showed that the starch granules from all cultivars of Canna were oval-shaped granules with smooth surfaces and were around $10-100 \mu \mathrm{m}$ in sizes. Proximate composition studies showed that the protein content in the Canna samples varied between 0.069 and $0.078 \%$, lipid between 0.014 and $0.019 \%$ and ash between 0.25 and $0.33 \%$. All Canna starches contained considerably high phosphorus (371-399ppm), followed by calcium (113-154ppm) and potassium (35-61ppm). The absolute amylose content ranged from 19 to $25 \%$. All three starches displayed a B-type X-ray diffraction pattern. The viscograms of Canna starches determined by Rapid Visco Analyzer showed that Thai-green and Japanese-green starches paste were quite stable during cooking and had high setback.

Molecular structures of starches isolated from Japanese-green, Thai-green and Thai-purple cultivars of edible Canna (Canna edulis Ker) were also investigated by Thitipraphunkul et al. ${ }^{3}$ (II) The absolute 
amylose content ranged from 19 to $25 \%$. Degrees of polymerization (DPn) values of amylose determined by fluorescence-labeling method were 1590 for Thai-purple, 1620 for Japanese-green and 1650 for Thai-green cultivars. Mole $\%$ of branched fraction of amyloses from edible Canna starches examined by a HPLC system after $\beta$-amylolysis of labeled amyloses was $13-16 \%$. Branch chain-length distributions of amylopectin analyzed by HPSEC after debranching with isoamylase, is followed by fluorescence-labeling of unit chain, showed bimodal distribution with the DPn range of 25-28. The amylopectin of edible Canna starches contained high amounts of organic phosphorus (391420ppm).

Piyachomkwan et al. ${ }^{4}$ evaluated Edible Canna (Canna edulis Ker) as an alternative starch source on the basis of genetic characteristics, agronomic traits and starch properties. Four Canna varieties indigenous to Thailand were examined including Thai-green, Japanese-green, Thai-purple and Chinese-purple and compared with cassava (Manihot esculenta Crantz). Using the Random Amplified Polymorphic DNA (RAPD) technique employing ten 10-base primers, four primers implied that at least three types of Canna including Thai-green, Japanese-green and Thai/Chinese-purple existed and corresponded to plant characteristics as identified by flower, stem, leaf and rhizome colors. Despite genetic diversification, starch properties were not variable. All four varieties produced 30.4-38.4 tonnes/ha of rhizomes with starch content about 13\% (wet basis). Starch yields of Canna (4.1-4.9tonnes/ha) were comparatively lower than cassava (6.5tonnes/ ha). The starches were characterized by giant granules $(10-80 \mu \mathrm{m})$, and compared with cassava starch pastes had a higher peak viscosity (930-1060BU for Canna starches and 815BU for cassava starch), occurring at a higher temperature. Pastes of Canna starch were more stable and when cooled, viscosity increased to 1800BU. Gelatinized pastes of Canna starches also rapidly formed good gels on cooling.

Propolis was mixed with ethanol at a ratio of 1:10 (w/v) for 24 hour to yield propolis ethanol extract by Wang et al. ${ }^{5}$ Extract was further fractionated with supercritical carbon dioxide $\left(\mathrm{SC}-\mathrm{CO}_{2}\right)$ into four fractions. To evaluate the selectivity of the fractionation, extracts corresponding to four fractions were characterized in terms of total flavonoid contents, antioxidant abilities and antioxidant mechanisms. Experimental results indicated that fractionation altered the composition distributions of fractions, e.g., by reducing total flavonoid contents. The antioxidant ability, metal chelating capacity, reducing power, and scavenging capacity of $\mathrm{DPPH}, \mathrm{O}_{2} \cdot{ }^{-}$or $\cdot \mathrm{OH}$ radicals of propolis extract and fractions increased with propolis concentrations. The effects of scavenging on DPPH of propolis extract and fractions, at $2 \mathrm{mg} / \mathrm{ml}$ were $(93 \%),(56 \%),(47 \%)$, and (27\%). At a concentration of $1 \mathrm{mg} / \mathrm{ml}$, propolis fractions scavenged $\mathrm{O}_{2} \cdot-$ by over $73 \%$ and all the fractions trapped around $65 \%$ of the $\cdot \mathrm{OH}$ groups. The importance of the antioxidants of plant origin and the methodologies used to evaluate their activity present an insight into some relevant antioxidant chemical families of plant origin, and finally into sources of antioxidants for the food industry.

Nutraceuticals for functional foods are focusing on the phytochemicals that possess antioxidant activities, their physiological functions and mechanisms of action in human disease prevention and health promotion.

Today the food industry has an extensive color palette available, allowing selection of the most suitable color for their application requirements. Color suppliers are however constantly striving to improve the technical and physical properties of their color portfolio, to make the use of color easier, to improve the stability and to meet customer demands on the functional additives used within color formulations and be "NATURAL" also. Downham and Collins has carried out a work to review all colors in terms of recent developments and regulations as well as addressing the question of the future of colors in the next millennium. ${ }^{6}$

Bandyopadhyay et al. ${ }^{7}$ showed antioxidant activities of beet (Beta vulgaris), mint (Mentha spicata L.) and ginger (Zingiber officinale $L$.) alone or in combination after their fortification in sandesh (a heat desiccated product of coagulated milk protein mass) using Randox's total antioxidant level determining chemicals and ultimately it was compared with the synthetic antioxidants like $t$-butyl hydroquinone (TBHQ), $t$-butyl-4-hydroxyanisole (BHA) and 2,6-di-t-butyl-phydroxytoluene (BHT). Addition of beet or mint alone in sandesh showed lower antioxidant level than the addition of ginger alone. However, combination of beet with ginger showed highest antioxidant level among the natural sources and value was almost equal to TBHQ $(200 \mathrm{mg} / \mathrm{kg})$. Besides, the suitable stage and form of addition of these herbs in sandesh were also investigated using the Randox's antioxidant level evaluating chemical. Among the four forms of herbs such as paste, tray-dried powder, freeze-dried powder and solvent extracted form, addition of solvent extracted form in sandesh showed highest antioxidant level than any other form. According to sensory characteristics, sandesh containing beet, ginger or combination of beet with ginger or mint was more acceptable to panelist than control sandesh. Results of the study indicate that herbal sandesh is more value added health food than control sandesh.

Canna indica has its use as dye (dye extracted from its flower) and Canna edulis as edible starch. Their property of being edible as well as giving coloring material will support its prospect as an edible dye.

\section{Antioxidant activity}

Different plant seeds extracts of Citrus sinensis, Hordeum sativum, Triticum sativum, Canna indica, Citrullus vulgaris and Capsicum annuum were evaluated for their antioxidant activity by the following methods: 2,2-diphenyl-1-pycril-hydrazyl (DPPH) radical scavenging, reducing power, $\mathrm{RBCs}$ hemolysis and linoleic acid oxidation, along with the determination of total phenolic and flavonoids contents. All the methanolic extracts showed high antioxidant activity and have high contents of phenolic and flavonoid. The Canna indica extract exhibited strong antioxidant as a reducing power and as DPPH radical-scavenging (3.61 absorbance, $87.12 \%$, respectively), while the Hordeum sativum extract exhibited highest inhibitory effect on RBCs hemolysis $(59.55 \%)$ and the Capsicum annuum extract has highest inhibitory effect on linoleic acid peroxidation $(65.06 \%)$ was reported by Atrooz. ${ }^{8}$

Vankar et al. ${ }^{9}$ evaluated a comparative study of antioxidant activity, phenol and flavonoid contents in Red, Yellow varieties of Canna indica and Hibiscus rosa sinensis, for proposing as prospective natural food dyes.

Food item always needed color sometime in aesthetic sense and sometimes their use being inevitable. In this respect coloring matter of $C$. indica having medicinal (antioxidant) property too, can suitably be used in edible products. However this approach will also boost use and production of natural products having medicinal properties, which eventually will lead to a healthy society and healthy body, needless to say that only a healthy body can retain a healthy brain. An intensive study is thus proposed on $C$. indica for its use as food dye having good antioxidant properties through molecular identification of the phytochemicals was carried out. 


\section{Use of dye extract of canna indica}

Vankar et al. ${ }^{10}$ reported their work on the exploitation of a natural colouring material from Canna indica flower (red variety) for cotton textile dyeing operation. Samples dyed with Canna have good fastness properties. The colour range obtained with canna was ranging from pinkish purple to dark purple by premordanting in stannic chloride. Sap green with Alum. Dark green by premordanting with ferrous sulphate and mustard yellow by post mordanting with ferrous sulphate. It was also reported that more concentrate dye extract if used could give better results.

Further on Vankar et al. ${ }^{11}$ reported that dissolution of partially insoluble natural canna dye in different mediums made cotton dyeing very easy and efficient. Aqueous, methanolic/ethanolic and oil/water microemulsion were the three medium used for the dissolution of the canna dye. The role of oil/water/surfactant emulsion in dye migration at the micelles for dissolution of canna dye from the ethanolic extract and further its release for better dyeability for dyeing cotton was a major breakthrough in the field of cotton dyeing. The ease of solubilization of canna dye in ethanol and its influence in dye exhaustion and fixation on cotton fabric was found to be the superior to the previously reported method by the same authors.

Ultrasound-assisted extraction in different solvents offered an effective alternative for simultaneous extraction of pigment and other phytochemical study of Canna indica was carried out by Vankar et al. ${ }^{12}$ This is the first report on the phytochemicals and antioxidant activity from Canna indica flowers particularly for its radical scavenging activity. It can be thus used as a good source of food additive both for color and antioxidant activity.

While evaluating the anthocyanin content in Red and Blue flowers, Vankar investigated the relative concentration of anthocyanins based on molecular polarity for different seasons of harvesting of blue and red flowers namely in (Table 1). ${ }^{13-15}$

Table I The relative concentration of anthocyanins based on molecular polarity for different seasons of flowers

\begin{tabular}{lll}
\hline $\begin{array}{l}\text { Serial } \\
\text { No. }\end{array}$ & Name of the plant & $\begin{array}{l}\text { Relation concentration of } \\
\text { anthocyanin TAC( } \mathbf{m g} / \mathbf{K g})\end{array}$ \\
\hline I & Canna indica & 96.29 \\
2 & Clitoria ternatea & 227.42 \\
3 & Delonix regia & 101.13 \\
4 & Hibiscus mutabilis & 52.94 \\
5 & Impatiens balsamina & 336.56 \\
6 & Ixora chinensis & 50.84 \\
7 & Jatropha integerrima & 152.82 \\
8 & Lagerstroemia indica & 36.22 \\
9 & Mirabilis jalapa & 338.61 \\
I0 & Nerium oleander & 55.94 \\
II & Portulaca graniflora & 131.96 \\
I2 & Quisqalis indica & 72.3 \\
I3 & Rosa indica & 64.52 \\
I4 & Ruellia tuberosa & 46.84 \\
I5 & Thunbergia erecta & 46.95 \\
\hline
\end{tabular}

The stability of anthocyanins extracted from these flowers at their different developmental stages, was evaluated mainly for the effects of $\mathrm{pH}$, storage period, temperature, storage period as well as light and dark conditions were evaluated. Fully formed but unopened flower bud had the highest amount of total anthocyanin extracted from fresh petals.

Canna indica flower extract has been used for dye sensitized solar cells (DSSC) and its efficiency in energy conversion has been $0.29 \%$ as reported by Luo. It was an efficient method of conversion of visible light to electrical energy.

There has been use of Canna indica flower extract as a natural indicator in acid-base titrations by Mahajan et al ${ }^{16}$ In case of weak acid and weak base titration, the results were equivalent to synthetic mixed indicators. Thus it is a cheap, simple and accurate source for natural indicators.

Saisomboon \& Siri-Upathum ${ }^{17}$ described a new method for measuring radiation dose by using natural pigments. The pigments were extracted from Canna indica and other flowers and were irradiated with gamma ray. Doses of $30 \mathrm{rad}$ and above are indicated by color changes, thereby using it as dye strip dosimeter.

\section{Phytoremediation}

Removal of chromium and nickel from aqueous solution in constructed wetland: Mass balance, adsorption-desorption and FTIR study was studied by Yadav et al. ${ }^{18}$ To investigate the chromium and nickel removal from aqueous solutions in constructed wetland microcosms using Canna indica Lin. species. Effects of different hydraulic retention times (HRTs), initial metal concentrations and depth of gravel beds on removal of chromium and nickel were studied. Maximum removal of chromium and nickel was found to be $98.3( \pm 0.32)$ and $96.2( \pm 1.52) \%$, respectively, at initial concentrations of $10 \mathrm{mg} \mathrm{l}^{-1}$ and at an HRT of $48 \mathrm{~h}$ in $0.95 \mathrm{~m}$ gravel bed depth constructed wetland microcosms.

Chemical fractionation and translocation of heavy metals in Canna indica $L$. grown on industrial waste amended soil was carried out by Bose et al. ${ }^{19}$ A pot experiment was carried out to assess the effect of different amendments of industrial sludge on the growth of Canna indica $L$. as well as the translocation potential of heavy metals of this plant. The accumulation of metals $(\mathrm{Cr}, \mathrm{Fe}, \mathrm{Cd}, \mathrm{Cu}, \mathrm{Ni}, \mathrm{Zn}$, $\mathrm{Mn}$ and $\mathrm{Pb}$ ) in different parts of $C$. indica $L$. grown on industrial sludge-amended soil increased with time and increasing doses of sludge amendments. Sequential extraction method was followed to estimate the different fractions of heavy metals in sludge-amended soils collected from different periods of this study. The results showed that $\mathrm{Mn}, \mathrm{Zn}, \mathrm{Cd}, \mathrm{Cr}$ and $\mathrm{Pb}$ were mostly associated with $\mathrm{Fe}-\mathrm{Mn}$ oxide fraction in all amendments, whereas, Ni was mostly found in residual (RES) fraction. $\mathrm{Cu}$ and $\mathrm{Fe}$ were found to be higher in organically bounded form (OM) and RES fraction. The metal concentration in C. indica L. after 90 days of experiment started, was in the order of $\mathrm{Fe}>\mathrm{Cr}>\mathrm{Mn}>\mathrm{Zn}>\mathrm{Ni}>\mathrm{Cu}>\mathrm{Cd}>\mathrm{Pb}$ and the metal translocation was found lesser in shoot. With the increasing percentage of sludge amendments in soil the metal concentrations increased in different parts of plants.

In situ phytoremediation of heavy metals: A sustainable approach for waste water monitoring in India was studied by Ramteke et al. ${ }^{20}$ Experimental fields were monitored for the existing plant species and water body contaminants. In situ, a number of plant species were found 
in investigations, aquatic plant species were found as heavy metals accumulator species, therefore their capabilities and diversity were further investigated in Eichornia crassipes, Lemna minor, Ipomoea aquatica, Typha angustifolia, Canna indica, Silense vulgaris, Clorella etc. The effect can be significant and in certain species, heavy metal accumulation can rapidly increase 10 -fold. Methods are described for the decontamination of water containing heavy metals. The methods are particularly directed at the decontamination of water containing lead, Copper, Chromium, Zinc, Cadmium, Nickel, and Cadmium etc.

Phytoremediation of triazophos by Canna indica Linn. In a hydroponic system was investigated by Cheng et al. ${ }^{21}$ The phytoremediation of triazophos (O, O-diethyl-O-(1-phenyl-1, 2, 4-triazole-3-base) sulfur phosphate, TAP) by Canna indica Linn. in a hydroponic system was studied. After $21 \mathrm{~d}$ of exposure, the removal kinetic constant $(\mathrm{K})$ of TAP was $0.0229-0.0339 \mathrm{~d}-1$ and the removal percentage of TAP was $41-55 \%$ in the plant system and the $\mathrm{K}$ and removal percentage of TAP were about $0.002 \mathrm{~d}-1$ and $1 \%$, respectively, in darkness and disinfected control. However, the K and removal percentage of TAP were $0.006 \mathrm{~d}-1$ and approximately $11 \%$, respectively, in the treatment with eluate from the media of constructed wetland. The contribution of plant to the remediation of TAP was $74 \%$ and Canna indica played the most important role in the hydroponic system. Under the stress of TAP and without inorganic phosphorus nutrient, the activity of phosphatase in the plant system increased and phytodegradation was observed. The production and release of phosphatase is seen as the key mechanism for Canna indica to degrade TAP.

Contaminant removal of domestic wastewater by constructed wetlands: Effects of plant species was studied by Yang et al. ${ }^{22}$ A comparative study of the efficiency of contaminant removal between five emergent plant species and between vegetated and unvegetated wetlands was conducted in small-scale $(2.0 \mathrm{~m} \times 1.0 \mathrm{~m} \times 0.7 \mathrm{~m}$,length $\times$ width $\times$ depth $)$ constructed wetlands for domestic wastewater treatment in order to evaluate the decontaminated effects of different wetland plants. There was generally a significant difference in the removal of total nitrogen $(\mathrm{TN})$ and total phosphorus (TP), but no significant difference in the removal of organic matter between vegetated and unvegetated wetlands. Wetlands planted with Canna indica Linn. Pennisetum purpureum Schum. and Phragmites communis Trin. had generally higher removal rates for TN and TP than wetlands planted with other species. Plant growth and fine root (root diameter $\leq 3 \mathrm{~mm}$ ) biomass were related to removal efficiency. Fine root biomass rather than the mass of the entire root system played an important role in wastewater treatment. Removal efficiency varied with season and plant growth. Wetlands vegetated by P. communis and Canna indica demonstrated higher removal efficiency from August to December. These findings suggest that abundance of fine roots is an important factor to consider in selecting for highly effective wetland plants. It also suggested that a plant community consisting of multiple plant species with different seasonal growth patterns and root characteristics may be able to enhance wetland performance.

Zang et al..$^{23}$ demonstrated that, using an air-cathode microbial fuel cell (MFC) inoculated with rumen microorganisms, electricity could be directly produced with a maximum power density of $0.405 \mathrm{~W} / \mathrm{m}^{3}$ from Canna indica, a lignocellulosic aquatic plant rich in cellulose, hemicellulose, and lignin, without pretreatment The mechanisms of the degradation in the MFC were elucidated through analyzing the changes of canna structure and intermediates, that is, soluble sugars and volatile fatty acids (VFAs), in the electricity generation process. The results showed that lignin was partially removed and more cellulose became exposed on the sample surface during the electricity generation in the MFC. The electron transfer in this MFC was mainly completed through electron shuttling via self-produced mediators. This work presents an attempt to understand how complex substrates like aquatic plants are decomposed in an MFC during electricity generation. It might hopefully, provide a promising way to utilize lignocellulosic biomass for energy generation.

Treatment of effluent from the recycled paper mill by using integrated vertical-flow constructed wetland using Canna indica by $\mathrm{Li}$ et al. ${ }^{24}$ Integrated vertical-flow constructed wetland was used in this investigation for the treatment of the effluent from the recycled paper mill. Eichhornia crassipes, Alternanthera philoxeroide, Phragmites communis and Canna indica L. were selected as constructed wetland plants and quartz sand, macadam and cobblestone were used as filler. Results showed that even plants harvesting will affect the treatment efficiency of the system, however the plants bed with multi-layer configuration still can decrease the pollutants effectively. When the $\mathrm{pH}$ value of influent was between 7.16 and 7.45; the average contents of $\mathrm{BOD}_{5}, \mathrm{COD}_{\mathrm{Cr}}$ and SS were $416 \mathrm{mg} / \mathrm{L}, 543 \mathrm{mg} / \mathrm{L}, 429 \mathrm{mg} / \mathrm{L}$, respectively; hydraulic load $0.053 \mathrm{~m}^{3} /\left(\mathrm{m}^{2} \cdot \mathrm{d}\right)$, the removal rates of $\mathrm{BOD}_{5}, \mathrm{COD}_{\mathrm{Cr}}$ and SS were $94.9 \%, 91.4 \%, 98.0 \%$ respectively. After 10 months operation, the main indexes of the effluent can meet "Discharge regulation of water pollutants for pulp and paper industry" (GB 3544-2008) and can be utilized for irrigation..$^{25}$

Side-by-side comparison of horizontal subsurface flow and free water surface flow constructed wetlands and artificial neural network (ANN) modelling approach was attempted by Naz (2009). A horizontal subsurface flow (HSSF) and a free water surface flow (FWSF) constructed wetlands $\left(4 \mathrm{~m}^{2}\right.$ of each) were set up on the campus of Harran University, Sanliurfa, Turkey. The main objective of the research was to compare the performance of two systems to decide the better one for future planning of wastewater treatment system on the campus. Both of the wetland systems were planted with Phragmites australis and Canna indica. During the observation period (10 months), environmental conditions such as $\mathrm{pH}$, temperature and total chemical oxygen demand (COD), soluble COD, total biochemical oxygen demand (BOD), soluble BOD, total suspended solids (TSS), total phosphate (TP), total nitrogen (TN) removal efficiencies of the systems were determined. According to the results, average yearly removal efficiencies for the HSSF and the FWSF, respectively, were as follows: total COD $(75.7 \%$ and $69.9 \%)$, soluble COD $(85.4 \%$ and $84.3 \%)$, total BOD (79.6\% and $87.6 \%)$, soluble BOD $(87.7 \%$ and $95.3 \%)$, TN $(33.2 \%$ and $39.4 \%)$, and TP $(31.5 \%$ and $6.5 \%)$. Soluble COD and BOD removal efficiencies of both systems increased gradually since the start-up. After nine months of operation, above $90 \%$ removal of organic matters was observed. The treatment performances of the HSSF were better than that of the FWSF with regard to the removal of suspended solids and total COD at especially high temperatures.

\section{Acknowledgements}

None.

\section{Conflict of interest}

Authors declare there is no conflict of interest in publishing the article. 


\section{References}

1. Stintzing FC, Carle R. Functional properties of anthocyanins and betalains in plants, food, and in human nutrition. Trends in Food Science \& Technology. 2004;15(1):19-38.

2. Thitipraphunkul K, Uttapap D, Piyachomkwan K, et al. A comparative study of edible canna (Canna edulis) starch from different cultivars. Part I. Chemical composition and physicochemical properties. Carbohydrate Polymers. 2003;53(3):317-324.

3. Thitipraphunkul K, Uttapap D, Piyachomkwan K, et al. A comparative study of edible canna (Canna edulis) starch from different cultivars. Part II. Molecular structure of amylose and amylopectin. Carbohydrate Polymers. 2003;54(4):489-498.

4. Piyachomkwan K, Chotineeranat S, Kijkhunasatian C, et al. Edible canna (Canna edulis) as a complementary starch source to cassava for the starch industry. Industrial Crops and Products. 2002;16(1):11-21.

5. Wang BJ, Lien YH, Yu ZR. Supercritical fluid extractive fractionation - study of the antioxidant activities of propolis. Food Chemistry. 2004;86(2):237-243.

6. Downham A, Collins P. Colouring our foods in the last and next millennium. International Journal of Food Science \& Technology. 1999;35(1):5-22.

7. Bandyopadhyay M, Chakraborty R, Raychaudhuri U. A process for preparing a natural antioxidant enriched dairy product (Sandesh). LWTFood Science and Technology. 2007;40(5):842-851.

8. Atrooz OM. The antioxidant activity and polyphenolic contents of different plant seeds extracts. Pakistan J Biological Sciences. 2009;12(15):1063-1068.

9. Vankar PS, Srivastava J. Comparative Study of Antioxidant activity, Phenol and Flavonoid contents in Red, Yellow varieties of Canna indica and Hibiscus rosa sinensis, prospective natural food dyes. International J Food Engineering. 2008;4(3).

10. Vankar PS, Ghorpade B, Tiwari V. Ultrasound Energised dyeing of Cotton fabric with Canna Flower extracts using Ecofriendly mordants. Asian Textile J. 2000;68-69.

11. Vankar PS, Seth R, Srivastava J. Solubilisation of red pigments from Canna Indica flower in different media and cotton fabric dyeing. International Dyers. 2008;193(1):31-36.

12. Vankar PS, Srivastava J. Ultrasound-Assisted extraction in different solvents for phytochemical study of Canna indica. International J Food Engineering. 2010;6(3).
13. Vankar PS, Srivastava J. Evaluation of Anthocyanin Content in Red and Blue flowers. International J Food Engineering. 2010;6(4).

14. Vankar PS, Srivastava J. Methylated Anthocyanidin glycosides from flowers of Canna indica. Carbohydr Res. 2010; 345(14):2023-9.

15. Vankar PS, Srivastava J. New Anthocyanins pigments isolated from Red variety of Canna indica flower accepted in Plant Physiology and Biochemistry article in press. 2010.

16. Mahajan NS, Jadhav RL, Pimpodkar NV, et al. Use of Canna indica flower extract as a natural indicator in Acid-base Titration. J Pharmacy Research. 2008;1(1):84-87.

17. Saisomboon S, Siri-Upathum C. Dye strip dosimeter. Review of Scientific Instruments. 1987;58(10):1951-1952.

18. Yadav AK, Kumar N, Sreekrishnan TR, et al. Removal of chromium and nickel from aqueous solution in constructed wetland: Mass balance, adsorption-desorption and FTIR study. Chemical Engineering $J$. 2010;160(1):122-128.

19. Bose S, Jain A, Rai V, et al. Chemical fractionation and translocation of heavy metals in Canna indica L. grown on industrial waste amended soil. J Hazard Mater. 2008;160(1);187-193.

20. Ramteke DD, Nagrale VD, Ramteke MD. In situ phytoremediation of heavy metals: A sustainable approaach for waste water monitoring in India. Research J Biotechnology. 2008;3:305-308.

21. Cheng S, Xiao J, Xiao H, et al. Phytoremediation of triazophos by Canna indica Linn. In a hydroponic system. International $J$ Phytoremediation. 2007;9(6):453-463.

22. Yang Q, Chen ZH, Zhao JG, et al. Contaminant removal of domestic wastewater by constructed wetlands: Effects of plant species. $J$ Integrative Plant Biology. 2007;49(4):437-446.

23. Zang GL, Sheng GP, Tong ZH, et al. Direct electricity recovery from Canna indica by an air-cathode microbial fuel cell inoculated with rumen microorganisms. Environmental Science \& Technology. 2010;44(7):2715-2720.

24. Li LN, Li YZ, Da LJ, et al. Treatment of effluent from the recycled paper mill by using integrated vertical-flow constructed wetland. Chung-kuo Tsao Chih/China Pulp and Paper. 2009;28(9):43-46.

25. Huang SP, Shieh GJ, Ko JL, et al. Inhibition of subgenomic hepatitis $\mathrm{C}$ virus RNA transcription by chinese herbal extracts. Pharmaceutical Biology. 2009;47(2):111-119. 